\title{
Fire Emergency Evacuation Simulation of a shopping mall using Fire Dynamic Simulator (FDS)
}

\author{
Easir A Khan*, Mohammad Abir Ahmed, Emamul Haque Khan, Suvash C. Majumder \\ Department of Chemical Engineering, Bangladesh University of Engineering and Technology (BUET), \\ Dhaka-1000, Bangladesh *Email: eakhan@che.buet.ac.bd
}

\begin{abstract}
Fire accident in a shopping mall, garments factory and other labor intensive industries nowadays has become a common incident in Bangladesh and poses a great threat to life, facilities and economy of our country. In this work, fire and evacuation simulation was performed for a single stored shopping complex utilizing computational fluid dynamic techniques. Fire Dynamic Simulator with evacuation (FDS+Evac) software was used to simulate a shopping mall fire and study the effects of fire on the emergency egress process of people. The shopping mall of area $64 \mathrm{~m}^{2}$ comprises of seven rooms with a pool fire at the center of the mall is modeled for simulation. The total evacuation time (TET) for a fixed population density were estimated with the change of heat release rate, soot yield, soot density and the design pattern or geometry of shopping mall. The evacuation of agents in different time and different design pattern of the mall has been assessed using the data obtained from the simulation. FDS+Evac provides an integrating platform where the interaction between fire growth and evacuees can be taken into account by simultaneous simulation allowing a full coupling of the fire conditions and human behavior. This makes FDS is an effective tool for simulating large and high density crowds where the movement dynamics of evacuees is affected by the crowd pressure. Full scale fire experiment is often quite difficult to study the fine and crowds evacuation behavior. This paper illustrates a promising application of fire dynamic simulator (FDS+Evac) for fire and evacuation modeling to predict the total evacuation time.
\end{abstract}

Keywords: Fire Safety, Evacuation modeling, Fire Dynamic Simulator and FDS+Evac

\section{Introduction}

Fire incidents occur frequently around the country and causes fatalities, severe burn injuries, and property damage. The country's worst inferno (on June 3,2010 ) in Dhaka city known as Nimtoly tragedy that originated from shop of flammable chemicals in ground floor of a residential building killed 124 and injured more than 100 people [1]. On March 13, 2009 fire broke out in the Boshundhara City Shopping Complex that killed seven people, injured more twenty people and damage several shops in six top floors. Fire incident again occurred in the same shopping complex in august 2016 injured several people and firefighter and caused significant damage of the sixth floor [2]. In 2017, a fire accident occurred at Dhaka North City Corporation market in Gulshan-1, Dhaka which completely destroyed and around 234 shops was burnt to ashes resulting a loss of around TK 500600 crore [3]. There were number of deadly fire incident occurred in ready-made garment industries in Bangladesh, e.g. KTS fire [4] and Tajrin fashion fire [5]. Investigations of these fire incidents confirm that these industries do not have adequate fire safety equipment and emergency exit route or planning. Workers died as they were unable to evacuate [5]. So it is very important to study the fire spreading behavior and emergency evacuation process to reduce the required evacuation time in case of fire.
Numerical fire simulation and evacuation modeling is used to study fire growth and emergency evacuation planning. Due to the loss of life and properties caused by fire accident, interest in fire safety in shopping mall has extended nationwide and researchers are studying those fire incidents to find a solution to this problem and incorporate safe evacuation pathways in future market designing. There has been significant effort to understand the fire growth behavior as the fire involve complex phenomenon comprising both chemical and physical processes. These processes are interactive in nature and non-linear which make it difficult to assess the fire spreading patterns of combustible materials.

For fire safety and emergency evacuation, the fire behavior inside buildings must be scientifically described and systemized as a theory, thereby allowing application to fire safety design of buildings. Fire behavior prediction in buildings largely depends on properties of combustibles such as the quantity, material, or exposed surface area of the combustible [6,7]. Quantity of combustibles depends on the purpose of the space while exposed surface area of combustibles depends on the type of the combustibles and the form of their storage. Properties of combustibles, which are important factors for design and evaluation of evacuation safety, include fire growth rate (fire spread speed), 
maximum heating rate of a single combustible, separation distance between combustibles (distribution of combustibles), and expansion of combustion of fixed combustibles such as ceiling and floor. With the advancement computational techniques, CFD based fire simulator has been developed to simulate the fire accident and to study the behavior of the fire. The application of fire simulator like FDS has been achieved great success for fire modeling during the last decades [812]. This simulator enables us to predict the pattern of fire, smoke pattern, heat released rate, the time required for evacuation and the effect of vent, sprinkler efficiency, positioning of source on the fire beforehand. Fire Dynamics Simulator (FDS) is extensively used to study fire spreading behavior and to implement this knowledge in mitigating the loss of lives and properties [12-15]. FDS+EVAC is well validated and demonstrated for emergency evacuation modeling in case of fire[16].

Experimental study of fire spreading patterns and emergency evacuation behavior is quite difficult to conduct especially for large establishment. The main objectives of the study are to simulate a fire incident in a market place with the help of Fire Dynamics Simulator (FDS) and study different properties of fire such fire intensity, soot yield, as well as market geometry and population density. The effect of these parameters on fire on the egress process was investigated in this work.

\section{Models and Simulation}

\subsection{Introduction to FDS+EVAC}

FDS is a computational fluid dynamics (CFD) model of fire-driven fluid flow. The computer program solves numerically a large eddy simulation form of the Navier-Stokes equations appropriate for lowspeed, thermally-driven flow, with an emphasis on smoke and heat transport from fires, to describe the evolution of fire. FDS+Evac is doing some kind of an artificial molecular dynamics for the agents [17]. The forces acting on the agents consist of both physical forces, such as contact forces and gravity, and psychological forces exerted by the environment and other agents. The model behind the movement algorithm is the social force model introduced by Helbing's group. A modification of the model to describe better the shape of the human body was introduced by Langston et al.[18]

\subsection{Agent movement model}

Human behavior is very chaotic or at least very irregular and not predictable. It is suggested that the motion of pedestrian can be described as if they would be subject to social force. These forces are not directly exerted by the pedestrian's personal environment but they are a measure for the internal motivation of the individuals to perform certain actions. The main issues that affect the motion of crowds-

- An agent wants to reach a certain destination as comfortable as possible. Therefore, the agent can normally take a way without detours, i.e., the shortest possible way.

- The motion of an agent is influenced by other pedestrians. Especially, he/she keeps a certain distance from other pedestrians that depend on the pedestrian density and the desired speed. A pedestrian also keeps a certain distance from borders of buildings, walls, streets, obstacles, etc. Agent feels the more uncomfortable the closer to a border he/she walks since he/she has to pay more attention to avoid the danger of getting hurt, e.g. by accidentally touching a wall.

- Pedestrians are sometimes attracted by other persons (friends, street artists, etc.) or objects (e.g. window displays).

According to this model the movement of the agent governed by the following equation [16]:

$m_{i} \frac{d^{2} x_{i}}{d t^{2}}=f_{i}(t)+\epsilon_{i}(t)$

where $\mathbf{x}_{i}(t)$ is the position of the agent iat time $t, \mathbf{f}_{i}(t)$ is the force exerted on the agent by the surroundings, $m_{i}$ is the mass, and the last term, $\xi_{i}(t)$, is a small random fluctuation force. The velocity of the agent, $\mathbf{v}_{i}(t)$, is given by $d \mathbf{x}_{i} / d t$.

The force on the agent $i$, has many components[16]:

$$
\begin{aligned}
& f_{i}=\frac{m_{i}}{T_{i}}\left(V_{i}^{o}-V_{i}\right)+\sum_{j \neq i}\left(f_{i j}^{s o c}+f_{i j}^{c}+f_{i j}^{w t}\right)+\sum_{w}\left(f_{i w}^{s o c}\right. \\
& \left.+f_{i w}^{c}\right)+\sum_{k}\left(f_{i k}^{w t}\right)
\end{aligned}
$$

where the first sum describes agent-agent interactions, the sum over $w$ describes agent- wall interactions, and the terms in the last sum, $\mathbf{f}_{i k}{ }^{\text {att }}$, may be used for other agent- environment interactions, like the fire-agent repulsion. The first term on the right-hand side describes the motive force on the evacuating agent. Number of agents considered for this simulation of egress process was 100 in $64 \mathrm{~m}^{2}$ compartment area. Among them the number of male, female, child and adult taken randomly are given in the below Table.1. bel:

\begin{tabular}{lc} 
Table 1. Number of different Types of agent \\
\hline Types & Number of agent \\
\hline Male & 25 \\
Female & 25 \\
Child & 25 \\
Adult & 25 \\
\hline Total & 100 \\
\hline
\end{tabular}




\subsection{Simulation Details}

A single stored shopping mall with seven rooms with different dimension as shown in Table.2 was modeled in FDS interface. The FDS-SMV interface of simulated shopping complex is shown in Fig.1.The green indicator of Fig.1 shows the only exit route of simulated shopping complex. The inner and outer material of construction is gypsum. Total area of compartment is $64 \mathrm{~m}^{2}$. Three occupant loadings $0.94,1.56$ and 2.50 per $\mathrm{m}^{2}$ are used in this simulation.

Table.2 Dimension of different room

\begin{tabular}{ccccc}
\hline $\begin{array}{c}\text { Room } \\
\text { No. }\end{array}$ & $\begin{array}{c}\text { Length } \\
(\mathrm{m})\end{array}$ & $\begin{array}{c}\text { Width } \\
(\mathrm{m})\end{array}$ & $\begin{array}{c}\text { Height } \\
(\mathrm{m})\end{array}$ & $\begin{array}{c}\text { Door } \\
\text { Width }(\mathrm{m})\end{array}$ \\
\hline 1 & 3.2 & 2.8 & & 1 \\
2 & 2.6 & 2.8 & & 1 \\
3 & 3.8 & 3.8 & & 0.8 \\
4 & 1.9 & 3.0 & 2.4 & 1.2 \\
5 & 3.9 & 3.0 & & 0.8 \\
6 & 2.8 & 3.0 & & 1 \\
7 & 2.8 & 3.0 & & 1 \\
\hline
\end{tabular}

\subsection{Fire scenario}

A fire source is placed in the middle of the compartment in a fixed location. Pool fire was used in simulation as shown in Fig.2. A pool fire is a turbulent diffusion fire burning above a horizontal pool of vaporizing hydrocarbon fuel where the fuel has zero or low initial momentum. For the simplicity of calculation, it is assumed that Heat release rate per unit area is constant as $1 \mathrm{MW}$. The fire source has been specified as,

$\begin{array}{ll}\text { Fire type } & \text { Burner } \\ \text { Fuel type } & \text { Propane } \\ \text { Area of pool fire } & 1 \mathrm{~m}^{2} \\ \text { HRRPUA } & 1000 \\ \text { Soot yield } & 0.1 \\ \text { CO yield } & 0.05\end{array}$

\subsection{Simulation scenario}

The evacuation performance was studied for seven scenarios of different controlled parameters such HRR, mass density, soot yield and geometry of the compartment. The total evacuation time (TET) was calculated for each of the scenarios. The controlled parameters of each scenario from S1 to S8 were provided in Table.3.

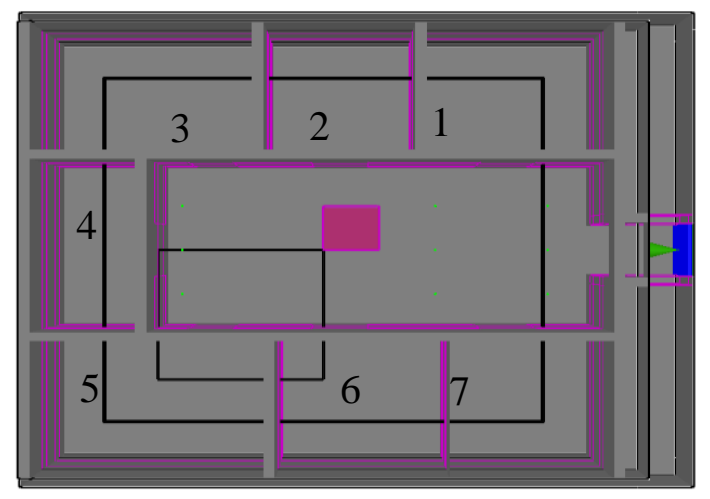

Fig.1. Top view simulated rooms in FDS interface

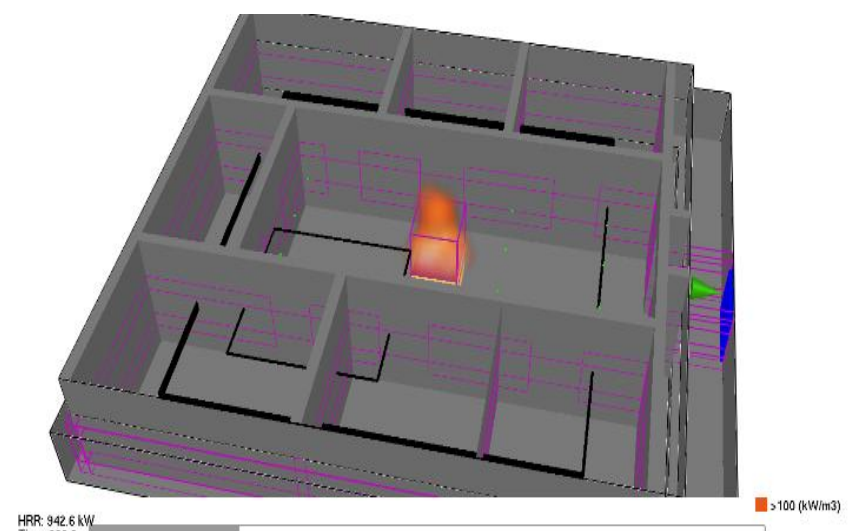

Fig.2: Fire view in simulator interface

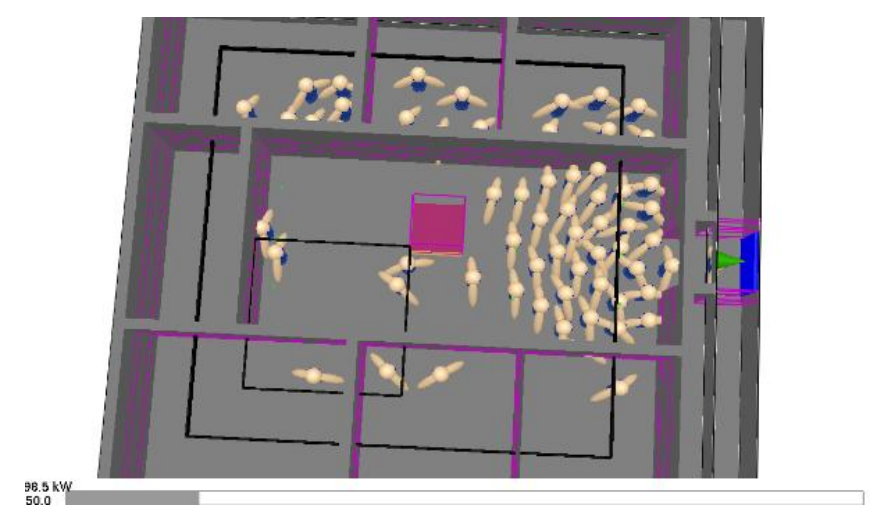

Fig.3: Evacuation view in simulator interface

Table 3: Simulation scenario for different controlled parameters

\begin{tabular}{cccccc}
\hline $\begin{array}{c}\text { Simulation } \\
\text { scenario }\end{array}$ & HRR $(\mathrm{kW})$ & $\begin{array}{c}\text { Mass Density } \\
\left(\text { Agent per } \mathrm{m}^{2}\right)\end{array}$ & Soot yield & $\begin{array}{c}\text { Exit Door } \\
\text { width }(\mathrm{m})\end{array}$ & $\begin{array}{c}\text { Number of Exit } \\
\text { door }\end{array}$ \\
\hline S1 & 1000 & 0.94 & 0.1 & 1.2 & 1 \\
S2 & 1000 & 1.56 & 0.1 & 1.2 & 1 \\
S3 & 1000 & 2.50 & 0.1 & 1.2 & 1 \\
S4 & 1000 & 1.56 & 0.05 & 1.2 & 1 \\
S5 & 1000 & 1.56 & 0.1 & 2.2 & 2 \\
S6 & 1000 & 1.56 & 0.1 & 1.2 & 1 \\
S7 & 200 & 1.56 & 0.1 & 1.2 & \\
\hline
\end{tabular}




\subsection{Steps of the simulation procedures}

The simulation of FDS+EVAC has three main steps: at first an input file has to be created in a text file, then run the simulation file and analyze the simulation results. The details steps of simulation are as follows,

- Define all geometric information of model compartment which include wall, ceilings, doors, windows, ventilations, exit routes as shown in Fig.1.

- Set the location of fire source and define the thermal properties and reaction properties of combustible materials or fuel.

- Define of the type of agents and agent loading parameters

- Define the meshes for fire and evacuation

- Set the device point for measurement of different parameters

- Set the run time and perform the simulations

- Analyze the simulation results

\section{Results and Analysis}

The simulations run for $900 \mathrm{sec}$ for each of the scenarios. Fire location was fixed for all the scenarios considered in this simulation. The heat release rate for scenario $\mathrm{S} 1$ to $\mathrm{S} 6$ is constant as $1000 \mathrm{~kW}$ as shown in Fig.4 and for S7, HRR was reduced to $200 \mathrm{~kW}$ to study the effects of HRR on the total evacuation time.

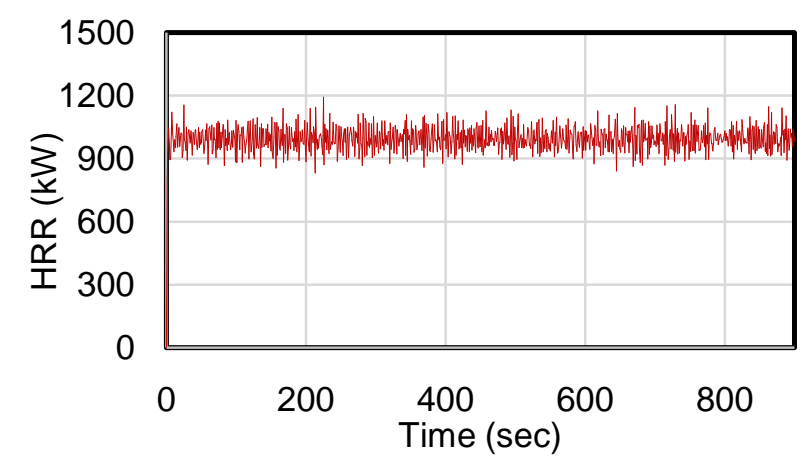

Fig. 4: Heat release rate in case fire for scenario $S 1$ to $\mathrm{S} 6$

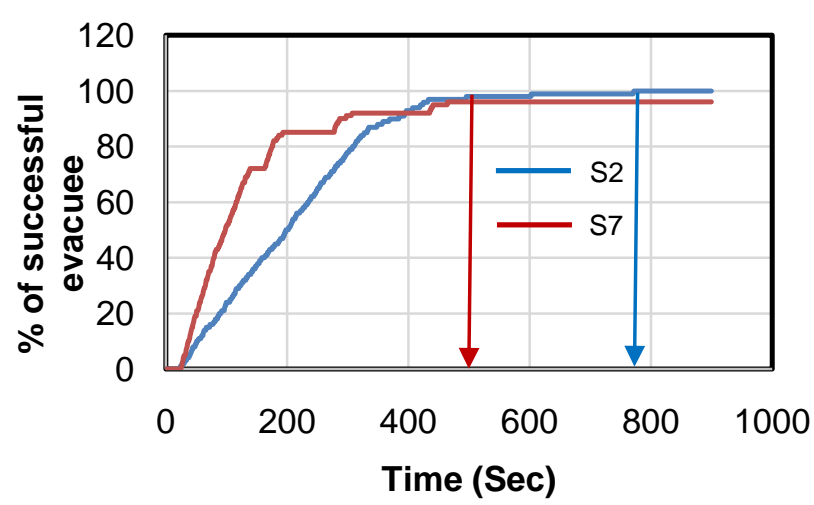

Fig.5: Effect of heat release rate on evacuation time.
Reduction of heat release rate has positive impact on emergency evacuation process. Comparing the case scenario between S2 and S7 as shown in Fig.5, the evacuation rate was significantly increased for S7 in case lower HRR and TET was also decreased to $500 \mathrm{sec}$.

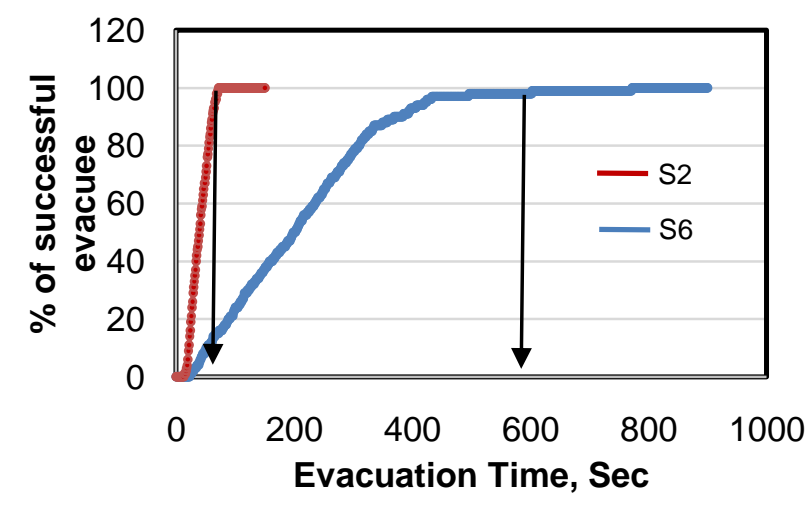

Fig.6: Effect of exit door width in evacuation time.

The fasted evacuation rate was found for simulation case S6. In this case two exit doors were used for emergency evacuation purpose. The total evacuation time required for this only $80 \mathrm{sec}$ where as TET $780 \mathrm{sec}$ is required for one exit doors as shown in Fig.6. This emphasize the presence multiple exit routes for ensuring faster emergency evacuation. In many incidents of RMG industries in Bangladesh, workers were unable to evacuate due to inadequate exit routes or emergency planning in case fire and eventually became unconscious and burnt to ashes $[5,19]$.

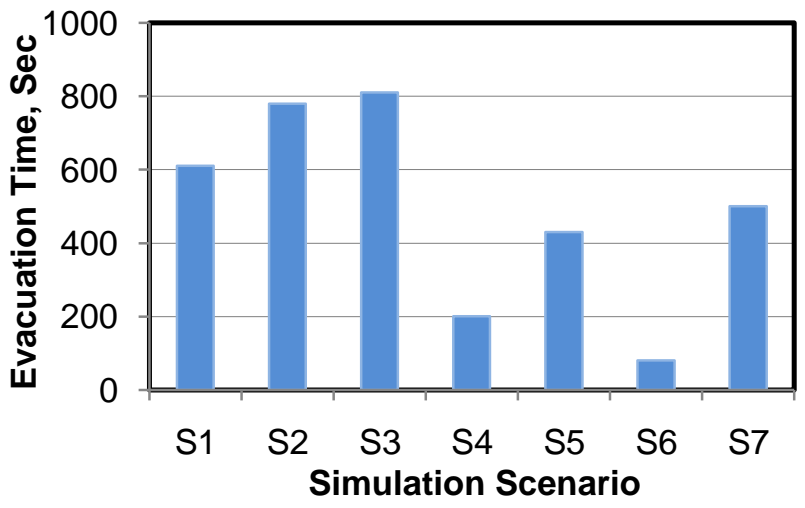

Fig.7: Estimated total evacuation time (TET) for all seven simulation scenarios

The evacuee movement ability is greatly affected by the thermal and reaction properties of fuel. Visibility of evacuee is deteriorated in presence of higher soot concentration. Comparing simulation results between scenario S2 and S4 as shown in Fig.7, the TET for S4 was 200 seconds where soot yield was 0.05 . If soot yield is increased to 0.1 , the TET is increased to 780 seconds. Soot formation of combustible materials depends on the fuel type and significantly influences the total evacuation time. 
Therefore design of a shopping mall and is emergency evacuation planning must consider the type and reaction properties of combustible materials stored in the facilities. In simulation, the exit door width was initially $1.2 \mathrm{~m}$ (for S2). With the increase it to $2.2 \mathrm{~m}$ (for S5) as shown in Fig.7, total evacuation time is reduced to $450 \mathrm{sec}$. If the door is wide enough then people could easily get past the door and there will be no congestion in the door area. Thus, for faster evacuation, the exit door should be wide enough so that people can evacuate easily.

\section{Conclusion}

This work successfully demonstration the fire emergency evacuation simulation of a single stored shopping center comprise of seven rooms. The effect of building geometry or design parameters on total evacuation time was evaluated analyzing the simulated results. The effect of fuel type and its thermal and reaction properties also greatly influenced the evacuee's movement and total evacuation time of certain number and type of agents. Pool fire with constant heat release rate was used in simulation. However, the actual heat release rate data from the presence of combustible materials for a facility would provides more realistic data for evaluating the emergency evacuation performance. Thus, the results obtained from (FDS+EVAC) simulation are particularly useful in designing a facility with fire and emergency evacuation Safety.

\section{Acknowledgement}

FDS-SMV open source software support from National Institute of Science and Technology, USA is gratefully acknowledged.

\section{References}

1. Hossain, F., Bangladesh fire races through buildings, kills 117. The Associated Press, 2010.

2. Fire again at Bashundhara City mall. http://www.thedailystar.net/city/fire-breaks-outbashundhara-city-1273249, 2016.

3. Fire razes DNCC market. http://www.newagebd.net/article/6181/firerazes-dncc-market, 2017.

4. skeers, J., Bangladesh: 54 workers killed in textile factory fire. https://www.wsws.org/en/articles/2006/03/bangm02.html, 2006.

5. Tazreen Fire - the Ground Realities. http://www.amrc.org.hk/sites/default/files/Tazree n\%20Report_0.pdf.
6. Ronchi, E., Testing the predictive capabilities of evacuation models for tunnel fire safety analysis. Safety Science, 2013. 59(Supplement C): p. 141-153.

7. Seo, D., et al., An Experimental Study on the Combustibles Investigation and Fire Growth Rate for Predicting Initial Fire Behavior in Building. Procedia Engineering, 2013. 62(Supplement C): p. 671-679.

8. Shen, T.-S., Y.-H. Huang, and S.-W. Chien, Using fire dynamic simulation (FDS) to reconstruct an arson fire scene. Building and Environment, 2008. 43(6): p. 1036-1045.

9. Yuen, A.C.Y., et al., Fire scene investigation of an arson fire incident using computational fluid dynamics based fire simulation. Building Simulation, 2014. 7(5): p. 477-487.

10. Yuen, A.C.Y., et al., Fire scene reconstruction of a furnished compartment room in a house fire. Case Studies in Fire Safety, 2014. 1(Supplement C): p. 29-35.

11. Xing, Z. and Y. Tang, Simulation of Fire and Evacuation in High-Rise Building. Procedia Engineering, 2012. 45(Supplement C): p. 705709.

12. Wahlqvist, J. and P. van Hees, Validation of FDS for large-scale well-confined mechanically ventilated fire scenarios with emphasis on predicting ventilation system behavior. Fire Safety Journal, 2013. 62(Part B): p. 102-114.

13. Li, Y., et al., Personnel evacuation research of subway transfer station based on fire environment. Procedia Engineering, 2017. 205(Supplement C): p. 431-437.

14. Ye, X., et al., Suppression Effect of Sprinkler System on Fire Spread in Large Commercial Buildings. Procedia Engineering, 2016. 135(Supplement C): p. 455-462.

15. Zhilei, W., et al., Simulation Research on Human Evacuation in Subway with a Singlepoint Fire Scenario. Procedia Engineering, 2014. 84(Supplement C): p. 595-602.

16. Simo Hostikka, T.K., Tuomas Paloposki, Tuomo Rinne, Katri Matikainen \& Simo Heliövaara, Development and validation of FDS+Evac for evacuation simulations. 2007.

17. Korhonen, T., et al., FDS+Evac: An Agent Based Fire Evacuation Model, in Pedestrian and Evacuation Dynamics 2008. 2008, Springer Berlin Heidelberg: Berlin, Heidelberg. p. 109120.

18. Langston, P.A., R. Masling, and B.N. Asmar, Crowd dynamics discrete element multi-circle model. Safety Science, 2006. 44(5): p. 395-417.

19. Pratap, S., Bangladesh Garment Industry in Turmoil: Workers No More Willing to Perish in the Profit Machine. Centre for Workers Education, 2011. 